$\begin{gathered}\text { EPiC Series in Education Science } \\ \text { Volume 1, 2017, Pages 427-438 }\end{gathered}$
$\begin{gathered}\text { AUBEA 2017: Australasian Universities Build- } \\ \text { ing Education Association Conference 2017 }\end{gathered}$

\title{
Implications of Building Accidents in Urban Settings for Building Safety Studies
}

\author{
Festival Godwin Boateng \\ School of Global, Urban and Social Studies, RMIT University, Australia
}

\begin{abstract}
At the core of the review is the critique that the extant theoretical approach to the study of building accidents does not sufficiently address societal level influences of vulnerability for such phenomena. Using the collapse of buildings in urban settings as reference point, the review makes a case for why the omission is fatal.
\end{abstract}

Keywords: building/construction/structural accidents/failures, construction management, developing countries, sustainable cities; urban pathology

\section{Introduction}

Building safety research has taken a pre-emptive turn. It has shifted from the, hitherto, ex-post facto analysis of trigger events. The shift in focus is grounded in the recognition that whereas there is always a technical/physical explanation for a failure, the reasons failure occurs are often procedural. Therefore, today, building safety researchers and practitioners have rightly preoccupied themselves with specifying and analysing how organisational, managerial, and workplace factors create conditions for failures to occur, provoke or trigger them. This review argues that while the paradigm shift has led to increasing implementation of quality systems, detection and prevention of errors in advance, and improved construction management, the rampant collapse of buildings in urban settings raises some 
theoretical and policy questions that warrant a re-think of the focus of building safety conversation on organisational influences of vulnerability for failures.

After this brief introduction, the remainder of the article unfolds as follows: The next section explores the extant theoretical focus of building safety research. The subsequent one captures the issue of building accidents in urban settings. The final sections cover a discussion of the implications of the rising incidence of building accidents in rapidly urbanising settings for building safety research, and some recommended actions. The paper could not have been timely and important enough as it provokes and stimulates a systematic re-view of the literature/approaches to the study of causes of vulnerability for building risks at a time when they have become disturbingly recurrent.

\section{Theoretical focus of building safety research: A brief overview}

Hitherto, (still important though) not just building safety, but accident research broadly, was forensic or remedial in approach: It involved retroactive analysis of how past accidents had occurred and application of the knowledge gained for preventing the recurrence of the specific error(s) that caused them. It was, thus, task or activity - based and backward-looking (Pidgeon, 2010). Much of the knowledge used to design, construct, manufacture, and operate engineered facilities and products were obtained through learning from failures. The problem, however, was that causes of accidents were known only after the fact. Second, it led to what is called in accident research circles as "tokenism" - as it only provided insights to address specific errors. Further, what mainly featured in the post-accident investigations were usually the immediate errors and violations, which, however, were just the triggering conditions for the manifestation of the accident/failure (Reason, 1990; Perrow, 1984). 
It was realised that the triggering factors (also called active failures) were rarely the principal instigators of failures. Instead, the real causes were weaknesses created by fallible decisions made earlier in the organisational and managerial spheres (Reason, 2000; 1990). Indeed, studies on failures and accidents increasingly reported human and organisational factors as the major causes-only a few cases were due to the absence of technology or the state of the art (Minato, 2003; Atkinson, 2002).

With the increasing recognition that whereas there is always a technical/physical explanation for a failure, the reasons they occurred were often procedural (Yates \& Lockley, 2002), building safety research and practitioners began focusing on identifying and neutralising latent failures -workplace, managerial, and organisational factors that combine with triggering events for them to manifest.

The late Barry Turner's seminal work: "Man-Made Disasters" (1978) is widely acknowledged to have marked the theoretical focus on organisational aetiology of vulnerability for failures. Based on a systematic qualitative analysis of a set of 84 British accident inquiry reports spanning a 10-year period, Turner found that failures were neither chance nor purely technical events. Rather, they arise, he noted, from an interaction between the human and organisational arrangements of the sociotechnical systems set up to manage complex and ill-structured risk problems (Turner, 1978; Pidgeon et al, 1988). Turner's work raised for the first time many of the key issues now taken for granted in the ongoing theoretical understanding of organisationally induced crises, vulnerability for accidents (Pidgeon, 2010; Blockley, 1999; Reason, 1990; Perrow, 1984).

Today, construction and building safety researchers are investigating construction firms' managerial, workplace and other organisational preconditions that enhance or create vulnerability for failures to occur in order to neutralise them (Minato, 2003; Andi \& Minato, 2004; Atkinson \& Westall, 2010; Atkinson, 2002). The paradigm 
shift has led to improved efforts towards reducing construction and building accidents. However, since the focus is on organisational influences of vulnerability, the intervention prescriptions that emanate from this theoretical conversation usually are directed at addressing workplace, managerial and other organisational level factors that implicate on failures.

\section{Building accidents in urban settings: A global overview}

There is not enough information or data on building accidents vis-à-vis their locations, yet. However, a fact-check of the locations of almost every media report on building collapse and those reported in published studies shows a rather revealing trend: building accidents mostly occur in urban settings. Thus, the occurrence of building collapse incidents is marked by a profound trend: they mostly occur in urban areas. A random recount of a few cases may be helpful. In the global north, some of the classic cases that commend to attention immediately may include the Versailles Wedding Hall collapse- the worst civil disaster in Israel's history that killed 23 people and injured another 380 in Jerusalem, the capital. In the US, one may point to the infamous collapse of the Hyatt Regency in Kansas City, Missouri, which killed 114 and injured 200 people at a tea dance. Wardhana \& Hadipriono (2003) also analysed 225 cases spanning from 1989 - 2000. The numbers suggest that the collapses usually occurred at the heart of some of the big states-California, Texas, New York, Florida, Illinois, Pennsylvania, Ohio, Georgia, North Carolina and New Jersey. Further, the collapse of the 5-story Sampoong Department Store in the Seocho District of Seoul, South Korea, resulted in the deaths of 502 people. The Seocho District, the incident location, is one of the 25 administrative units that make up the city of Seoul where over 10million people reside.

Still, in the global north, a growing chorus of building experts in Australia have deplored what they project, as imminent "endemic failure of the building industry" if the growing trend of faulty building construction is not addressed. They bemoan on 
the case of Melbourne - the capital and most populous city of the Australian state of Victoria, and the second-most populous city in Australia (Dow, 2016).

In the global south, where the incidents are even more rampant, some of the classic cases in Asia - the earth's most populous continent include the collapse of the Royal Plaza Hotel in the city of Nakhon Ratchasima (Korat) in Thailand, which killed 137 people and injured another 227. Yet again, the location of the incident Korat, one of the four major cities of Isan, is an urban setting. The Ranza Plaza incident that killed and injured 1,129 and 2,515 people, respectively in April 2013 occurred in the Bangladesh capital, Dhaka. As Ranza Planza was tumbling in Bangladesh, their neighbours in India, Mumbra, had experienced the worst building collapse incident in the area. About 74 people died, including 18 children. The incident location is a home to about one million people.

Others include the Selangor incident in Malaysia, where an apartment collapsed and killed about 48 people. Selangor (home to over 6million people) is one of the states on the west coast of Peninsular Malaysia, encircling the capital, Kuala Lumpur. In November 2015, a factory building collapsed in Lahore, the capital of Pakistani province of Punjab and killed about 45 people. Feifei (2014) has also compiled some cases in China and the trend shows that they usually occur in urban China.

In Africa -yet another hotspot for the incidents, Windapo \& Rotimi (2012) have compiled over 112 cases between December 1978 and April 2008 in Lagos alone, the largest city in Nigeria and on the African continent. Indeed, other Nigerian cities including Port Harcourt, Abuja, Enugu and Ibadan have also suffered many building accidents. The situation in Ghana is not different. The recent rampant building collapse incidents in the West African country is largely concentrated in urban Ghana -particularly Accra (the capital), and Kumasi, the second capital (Boateng, 2016). Tchamba \& Bikoko (2016) report of similar incidents in the urban settings of Cameroon in Central Africa. Alinaitwe and Ekolu (2014) examine similar cases in 
some East African countries' cities including Uganda, Kenya and Tanzania. Indeed, in April 2016, in Nairobi, the capital of Kenya, a six-storey building collapsed and killed over 49 people as many others sustained serious injuries.

Why are building accidents rampant in urban settings? What web of forces or broader connections in society account for that? Why are the incidents pervasive in developing (in contrast to advanced) countries? These questions and their corollaries raise theoretical and policy implications for the focus of building safety conversation on organisational aetiology of vulnerability for failures to which the paper turns shortly.

\section{Building accidents in urban settings: Implications for building safety research}

The cases presented above are just indicative, as there would not be enough space to cover even half of them. However, the broader point is that building accidents are at the heartland of today's urban crises, which, thus, poses imminent existential risks to the present and not-too distant future of urban life especially in the developing world where they mostly occur. The first risk associated with the trend of urban settings becoming the hotspots of the phenomenon is that the odds of more building accidents are growing by the day as the world is increasingly urbanising. The $21 \mathrm{st}$ century (projected to soon become the first urban century in human history Gottdiener \& Hutchison, 2006) is marked by the growing concentration of large swathes of people in urban settings with about $54 \%$ of the world's population currently living in such areas.

Two hundred years ago, Peking (today's Beijing) was the only city in the world with a population of a million people. Today, almost 500 cities are that big, and many are much bigger. The urban population of the world has grown rapidly from 746 million in 1950 to 3.9 billion in 2014. It is projected that urbanization combined 
with the overall growth of the world's population could add 2.5billion more people to urban populations by 2050 , with close to $90 \%$ of the increase to be concentrated in Asia and Africa - the hubs of developing countries where buildings collapse the most (Soane, 2016; Kumar, 2016).

Secondly, a significant share of global investments is trickling into the construction of buildings in urban areas (Roberts, 2016; Gottdiener \& Hutchison, 2006) obviously to meet the residential needs of the many of people thronging into such areas and provide the needed infrastructure to support the increased commercial activities.

Therefore, the rampant incidence of building accidents at such places could not be more worrying as a lot more people and massive investments stand at the risk of imminent peril. Policy measures to contain this looming danger may invariably need to be informed by an understanding of the connections in society that account for such places' high susceptibility to the accidents.

However, this is where the problem gets even more aggravated. The reason is that, as previously mentioned, since building safety conversation focuses on organisational aetiology of vulnerability for failures, the policy prescriptions center on addressing construction firms' managerial, workplace and other organisational preconditions that induce, provoke or trigger procedural errors and vulnerability for failures. The broader societal developments, processes and forces such as socioeconomic factors, competition and other market pressures, institutional, cultural and other influences of construction organisations and clients' suboptimal building practices and construction processes, which also are the ill-structured conditions and processes that eventually prefigure the accidents, either are discounted or insufficiently prioritised (Minato, 2003; Andi \& Minato, 2004; Atkinson, 1998).

Thus, the organisational aetiology of vulnerability approach to the study of building and construction failures theorises causes of vulnerability for failures without recourse to the enduring societal/environmental influences of suboptimal 
building practices and construction processes. In so doing, the approach decouples the phenomenon from the broader social contextual forces from whose interplay they emerge, which, therefore, denudes it of the capacity to confer insights into the broader connections in society that generate or create vulnerability for the accidents to occur and in this case their pervasiveness in urban settings.

\section{Conclusion and recommended actions}

The review has brought to the fore the rampant incidence of building accidents in rapidly urbanising settings especially in the developing world and has underscored its human security implications for our ever-urbanising world. It has been argued that the questions and cognate policy implications that the phenomenon raises are trans-organisational in nature and are, therefore, not amenable to the ongoing theoretical focus of building safety conversation on organisationally induced crises, vulnerability for failures.

Why are the accidents rampant in urban settings? What web of forces or broader connections in society account for that? Why are the accidents pervasive in developing countries? Answers to these questions and their corollaries, which are perforce for intervention efforts, are clearly beyond the scope and intervention prescriptions of the organisational aetiology of vulnerability for failures approach, which dominates building and construction safety conversations.

There is the need for a deeper level of analysis that problematises causes of vulnerability for the accidents within the broader patterns of society -against the backdrop of the broader societal developments, processes, pressures and factors that influence the demand/supply, design, construction, utilisation and adaptation of buildings and the regulation or poor or non-regulation of such practices and

processes. The ever-hot issue of urban building need pressures, commercialisation of residential buildings and the ongoing collusive practice of speedy construction and sanctioning of otherwise structurally incompetent buildings for factories and other 
related purposes in most cities in the developing world could serve as useful entry points for this enterprise.

First, regarding the issue of building need pressures, studies suggest that in the event of the dynamic pressure of urban population growth, the consequential upsurge in demand for housing and other building needs is met with frenzy, and in most cases, in an unsustainable way. This manifests in the proliferation of shoddy works; poor construction standards; building in dangerous locations, which together lead to the widespread creation of buildings with questionable integrity and in dangerous locations that eventually may collapse in the event, but also in even the absence of, physical hazards (Boateng, 2016; Escaleras et al, 2007).

Second, in respect of the commercialisation of residential buildings, some housing studies (see for instance, Oosterbaan et al, 2012) have reported of a rather dangerous widespread practice that has emerged in especially the cities developing in the global south, where residential buildings are frequently converted into commercial uses. However, the conversation on the development usually focuses on its adverse implications for urban housing. (The conversion of residential buildings for commercial purposes creates housing deficits). Nevertheless, the practice could have implications for building accidents. The argument is that since such structures originally were not intended for commercial use, the design considerations, regarding their fit for purpose, would normally not include the subsequent additional imposed loads associated with commercial use.

Finally, there is a growing collusive practice in developing countries, where local capitalists and public officials disregard regulations, construct and sanction otherwise structurally incompetent buildings for factories and other related purposes, which then lead to grisly accidents. The most infamous case is the collapse of the 
Rana Plaza textile factory building in April 2013 in Bangladesh, which killed 1,129 and injured 2,515 people.

The above issues could serve as useful entry points into the rampant occurrence of building disasters in urban settings. For instance, building safety researchers could deepen the conversation on urban housing pressures and the commercialisation of buildings: examine the underlying influences and the extent of their implications for generating vulnerability for accidents. Regarding the collapse of factories and similar buildings, an interesting dimension worth exploring is whether it has any linkages with global or international political economy developments such as the increased outflow of foreign direct investment, services and trade activities from the global north to the south. The global political economy has been marked by a seismic shift where corporations in the global North are now outsourcing production to the South for economy of scale reasons such as high cost of production in the West, relatively cheaper labour in the South. The increased outflows of foreign direct investment, services and trade activities have been a significant game changer as it is transforming the southern economies by creating jobs and opportunities for foreign exchange to resolve balance of payment deficits (See Lin, 2012). But is the growing adverse practice of constructing and sanctioning structurally incompetent buildings the unintended effect of this rather boon development emanating from the increased demand for buildings (for factories, retail and other services)?

A systematic examination of the above and similar broader societal influences of suboptimal building practices and construction processes could contribute to our understanding of why urban habitats are becoming the hotbeds of building accidents. The enterprise may worth the while, as some useful insights could be mined from it to affect regulatory and/or other interventions to address vulnerability for the 
accidents to save life and property, especially in the developing world where they do usually occur.

\section{Acknowledgments:}

I am grateful to my supervisory team: Dr Binoy Kampmark, Dr Robin Cameron and Dr Russell Solomon for their helpful comments. A special thank you to Emeritus Professor of Sociology, Gary Wickham of Murdoch University. Further, the helpful comments and suggestions offered by the reviewers are acknowledged.

\section{References}

Alinaitwe, H. M., \& Ekolu, S. (2014) Failure of structure in East Africa with focus on the causes of failures in the construction phase. In Construction Materials and Structures: Proceedings of the First International Conference on Construction Materials and Structures (p. 76).

Andi, \& Minato, T. (2004) Representing causal mechanism of defective designs: exploration through case studies. Construction Management and Economics, 22(2), 183-192.

Atkinson, A. R. (2002) The pathology of building defects; a human error approach. Engineering Construction and Architectural Management, 9(1), 53-61.

Atkinson, A. R., \& Westall, R. (2010) The relationship between integrated design and construction and safety on construction projects. Construction Management and Economics, 28(9), 1007-1017

Blockley, D.I. (1999) Man Made Disasters (Second Edition) by Brian A. Turner and Nick Pidgeon. Risk Management. Vol. 1 (1), pp. 73-75

Boateng, F. G. (2016) The Collapse of Buildings in Cities in Ghana: Reasoning Beyond 'Scientism'. In Refereed Proceedings of TASA 2016 Conference (p. 7).

Dow, A. (2016) Melbourne's faulty building crisis: Accessed: 28.01.17: http://www.theage.com.au/victoria/melbournes-faulty-buildingcrisis-20161217gtdbb0.html.

Escaleras, M., Anbarci, N., \& Register, C. A. (2007). Public sector corruption and major earthquakes: a potentially deadly interaction. Public Choice, 132(1), 209230.

Feifei, F. (2014) Overview of building collapses in China: Accessed: 28.01.17: http://www.chinadaily.com.cn/china/2014-04/04/content_17408943.htm. 
Gottdiener, M., Hutchison, R. (2006). The new urban sociology. Colorado: Westview Press.

Kumar, R.S. (2016) Lessons from structural failures in India. Proceedings of the Institution of Civil Engineers-Forensic Engineering, 169(4): 143 - 148.

Lin, J. Y. (2012) 'From Flying Geese to Leading Dragons: New Opportunities and Strategies for Structural Transformation in Developing Countries', Global Policy, Vol. 3(4): 397-409

Minato, T. (2003) Representing causal mechanism of defective designs: a system approach considering human errors. Construction Management and Economics, 21(3): 297-305

Oosterbaan, C., Arku, G., \& Asiedu, A. B. (2012) Conversion of residential units to commercial spaces in Accra, Ghana: a policy dilemma. International Planning Studies, 17(1), 45-66.

Perrow, C. (1984). Normal accidents: Living with high-risk systems. New Jersey: Princeton University Press

Pidgeon, N. (2010) Systems Thinking, Culture of Reliability and Safety. Civil Engineering and Environmental Systems, 27(3), 211-217.

Pidgeon, N.F., Blockley, D.I., and Turner, B.A. (1988) Site investigations: lessons from a late discovery of hazardous waste. The Structural Engineer, 66 (19): 311315.

Reason J. (2000) Human error: models and management. Western Journal of Medicine, 172(6): 393-6.

Reason, J. (1990) The contribution of latent human failures to the breakdown of complex systems. Philosophical Transactions of the Royal Society of London B: Biological Sciences, 327(1241), 475-484

Roberts, J. (2016) Global Cities 2016 Report.

Soane, A. (2016) Learning from experience to avoid collapse. Proceedings of the Institution of Civil Engineers-Forensic Engineering, 169(4): 127-132.

Tchamba, J. C., \& Bikoko, T. G. L. (2016) Failure and Collapse of Building Structures in the Cities of Yaoundé and Douala, Cameroon from 2010 to 2014. Modern Applied Science, 10(1): 23.

Turner, B.A. (1978) Man-Made Disasters. London: Wykeham Publications Ltd.

Wardhana, K., \& Hadipriono, F. C. (2003). Study of recent building failures in the United States. Journal of performance of constructed facilities, 17(3): 151-158.

Windapo, A. O., \& Rotimi, J. O. (2012) Contemporary issues in building collapse and its implications for sustainable development. Buildings, 2(3): 283-299.

Yates, J. K., \& Lockley, E. E. (2002) Documenting and analyzing construction failures. Journal of construction Engineering and management, 128(1): 8-17. 